\title{
Imagens e significados do banquete na Festa do Rosário
}

\author{
Célia Lucena*
}

\section{Notas introdutórias}

OBJETIVA-SE NESTE ARTIGO ANALISAR as imagens e os significados do banquete na festa popular, contidos na lógica da população de Silvianópolis, pequena cidade do sul-mineiro. Não se trata de forma alguma de beber e comer cotidianos de indivíduos comuns, trata-se de banquete que se desenrola na tradicional festa de Nossa Senhora do Rosário, no limite da fartura, da boa mesa e do apetite de comer em festa. Consideram-se neste estudo as seguintes dimensões: imagens e significados do banquete no festejo, papéis sociais e manutenção de hierarquias, sistema de troca e dádivas e a face ritualística da crença. "Esse comer coletivo, coroamento de um trabalho coletivo, não é um ato biológico, mas um acontecimento social." (Bakhtin, 2002, p. 246)

O estudo da alimentação ficou muito tempo na competência da antropologia e da história econômica, todavia, nos dias atuais, uma re-

* Professora do Departamento de História e responsável pelo Laboratório de História Oral, UNIVÁS-MG/; membro da Diretoria do CERU-USP.

1 Esta reflexão é resultado parcial do Projeto Sabor e festa: Dimensões simbólicas de banquetes em festejo. Coordenado pela profa Célia Lucena. LHO (Laboratório de História Oral), Departamento de História, UNIVÁS-MG. Depoimentos coletados no decorrer de 2003 com ajuda de alunos monitores do curso de História. Agradeço as críticas e reflexões feitas pelo prof. Daniel Camurça Correia e alunos monitores: Rodrigo Guimarães Lopes, Marco Paulo da Fonseca e João Uillian Vieira em reuniões de análises do material coletado em campo. 
volução documental associada aos novos temas das novas abordagens da historiografia contemporânea, permite-nos analisar a função cultural da alimentação, uma ideologia alimentar. O domínio cultural, criador do social, torna-se o lugar central dos conflitos, lugar das contradições, dos papéis sociais.

Sob a perspectiva das práticas culturais podemos enfatizar modos de cozinhar, técnicas, utensílios utilizados na preparação dos alimentos, tradições, papéis masculinos e femininos e ainda textos de receitas registrados na oralidade e na memória. As práticas culturais implicam adesão a um sistema de valores e comportamentos que forçam cada um a se conservar por trás de uma máscara para sair-se bem no seu papel. A maneira de cozinhar e os hábitos de servir a mesa são indicadores de uma adesão aos valores e comportamentos locais. Toda prática alimentar depende de uma rede de pulsões: quanto aos odores, cores e formas, também quanto ao tipo de consistência. O alimento escolhido, permitido e preferido é o lugar do empilhamento silencioso de toda estratificação de ordens e contra-ordens que dependem ao mesmo tempo de uma etno-história, de uma economia regional, de uma invenção cultural, de memórias e de experiências pessoais (Giard, 1996, p. 251-2).

Neste texto proponho-me a analisar imagens e significados do banquete na festa do Rosário, entendendo-a como uma atividade lúdica, um fenômeno da vida coletiva da pequena cidade mineira. Imagens e significados do festejo são enfocados a partir do comer coletivo no banquete servido aos congadeiros e ao público em geral trata-se de uma consagração extra-lógica, com uma temporalidade não linear, com códigos diferentes dos usuais. A festa é marcada pelo lúdico, por emoções oriundas de devoções, de ritos e de tradição. O reino do sagrado no festejo produz o efeito contagiante de aproximação entre as pessoas e a manutenção da celebração.

Esta pesquisa utiliza-se da metodologia de história oral, com entrevistas temáticas procurando entender junto à população o significado do banquete servido na festa do Rosário. Para isto são entrevistados: festeiros, cozinheiros, doceiras, congadeiros e moradores em geral. Sobre a questão das fontes orais, Alessandro Portelli afirma que "uma entrevista é uma troca entre dois sujeitos: literalmente uma visão mútua. Uma parte não pode realmente ver a outra a menos que a 
outra possa vê-lo ou vê-la em troca" (1997, p. 9). No momento da entrevista os significados e as imagens do festejo são construídos por meio de palavras, de gestos e de interpretações que expressam as maneiras de ser da população de Silvianópolis. As visões contidas nas interpretações entre dois sujeitos, entrevistado e entrevistador, são elementos básicos na construção das representações. Ao trabalhar com fontes orais o pesquisador tem oportunidade de lidar com as práticas com relação à forma, levando em conta a inventividade artesanal, o colorido das práticas culturais. Sistemas de valores que estruturam a lógica da população muitas vezes são despercebidos à consciência dos sujeitos, todavia, estes sistemas não podem passar despercebidos pelo pesquisador.

\section{O banquete como sistema de comunicação}

Os modos de cozinhar estão ligados ao modo de vida de uma população, à sua economia, à sua identidade e à sua cultura. Para Valeri: “a alimentação não é apenas a satisfação de uma necessidade fisiológica, mas também uma forma de comunicação, a ocasião das trocas e dos de ostentação, um conjunto de símbolos que constitui, para determinado grupo, um critério de identidade" (1987, p. 191). Podemos afirmar que é a sociabilidade que sobressai nos banquetes da Antiguidade. As festas litúrgicas do princípio da época suméria eram caracterizadas pelo banquete como uma reunião festiva da comunidade, momento importante de uma cerimônia, de regras de comportamento e de estreitar os laços entre festividades religiosas e profanas. Os aspectos essenciais do banquete na Mesopotâmia são ao mesmo tempo a reunião de um grupo que celebra sua solidariedade e a realização de um cerimonial já muito elaborado. Reunindo deuses, a corte real, os comensais, o que revela a hierarquia onipresente, a comida e a bebida circulam entre eles, originando uma troca de cortesias (Joannès, 1998, p. 66). Comemorações, a rigor, marcando tradição e lembranças, exigem comida, com toda cortesia ritual implícita na refeição. Os dias de festivais e banquetes são solenes e sagrados.

O banquete em Silvianópolis constitui o elemento de um sistema de trocas entre vizinhos, amigos, moradores, ex-moradores, visitantes, 
congadeiros, em que o acento da festa é colocado na preparação dos pratos que são servidos no comer coletivo e na visibilidade de cozinheiros e de festeiros organizadores do festejo. A refeição servida na festa do Rosário passa a ser um complexo culinário organizado, entendendo o banquete enquanto manifestação principal da vida organizada do lugar. A festa do Rosário é a maneira mais conhecida para mobilizar a população da cidade. O alimento tem um valor simbólico, é oferecido aos visitantes, e a concordância entre a avaliação do hospedeiro e do hóspede significa a continuidade das relações harmoniosas.

É no plano dos valores que a alimentação aparece como sistema, um conjunto orgânico. Os valores são expressos em termos de códigos, como o gustativo, a superioridade de uma receita sobre a outra, a sensibilidade em eleger um alimento "bom" ou "ruim". A alimentação é um sistema de comunicação cujos significantes estão relacionados a uma cultura regional (Valeri, 1989, p. 207). Os sistemas simbólicos são instrumentos de conhecimento e de comunicação, são um poder de construção da realidade. Os costumes que partilhamos, de cada prato que saboreamos, do comportamento à mesa, dizem respeito aos contextos regionais, étnicos e históricos específicos. A alimentação é uma forma de comunicação, constitui um critério de identidade.

A cozinha mineira consiste em habitus alimentares, sua análise implica na interpretação de práticas e representações característica do espaço da copa e cozinha - espaço da casa - privilegiado de convívio e de relações sociais. Procuramos perceber os movimentos do sabor da comida mineira por meio de uma perspectiva histórica. Sobre esta questão Abdala nos lembra: "o estudo da história possibilita perceber como se foram fixando padrões de convívio e hábitos alimentares que colocaram a cozinha como elemento central na caracterização de um típico mineiro" (1997, p. 16-7). Abdala acredita que tais hábitos reportam-se a uma tradição urdida no decorrer dos séculos XVIII e XIX, e que se estendeu até as primeiras décadas do século XX.

A cozinha regional expressa um modo de fazer particular, sua invenção em via de regra foi para responder uma necessidade ou uma lei local (Giard, 1998, p. 242). Os pratos regionais dependem muitas vezes de uma cozinha rústica, exigindo um cozimento regular, lento e longo, difícil de reproduzir na vida urbana. O banquete da festa do 
Rosário reforça nitidamente as práticas culinárias regionais, a cozinha mineira se presta aos banquetes de festa, com utensílios disponíveis, fogão a lenha e longo tempo de preparação.

Servir comida é uma marca da hospitalidade mineira, característica do mineiro, presente na literatura, relatos, crônicas e na memória popular. A devoção religiosa associada às trocas é uma característica mantida nas tradições mineiras. Barão de Eschwege em seu diário de uma viagem do Rio de Janeiro a Vila Rica, em 1811, faz um comentário sobre a comilança servida junto da paróquia em dia de festa: "junto da igreja estende-se um prédio destinado aos devotos que aqui se reúnem aos pés de Nossa Senhora; agora no dia da festa os administradores da igreja dão ali grande banquete" (1936, p. 37).

D. Isabel, moradora da cidade, que vem participando do festejo há anos como festeira, como moradora confirma a existência de devotos que se reúnem ao pé da santa; ao descrever o sistema de troca na festa, mostra os aparatos administrativos do festejo; aponta o papel dos festeiros como líderes e responsáveis pela manutenção do rito; reforça a habilidade necessária na personalidade dos festeiros para conseguir bons donativos para organização da boa mesa. A festa é comemorada todos os anos, sempre na segunda quinzena de junho. No segundo domingo do mês é o levantamento do mastro, marco religioso, início da festa; no último final de semana de junho, ocorre a festa do reinado, dos congadeiros e do banquete coletivo. Isabel relata:

"Para tirar esmola, precisa ser educado, agradar a pessoa para obter esmolas. (...) A festa quem faz é o povo. Deus abençoa e o povo ajuda a fazer. (...) A festa é pra todo mundo, pro povo da rua, pros congadeiros. Todo mundo come e bebe e doce à vontade. No fim da festa tem os doces, todo mundo vai lá com as latinhas, pra levar os doces embora. Porque o que a gente vai ficar fazendo com os doces, reparte com o povo. O sistema da festa é esse aí."

Trocas, dádivas e competência dos festeiros são elementos necessários no sistema da festa. Laços de solidariedade e generosidade coletiva são categorias instituídas pela comunidade local. 


\section{Trocas, dádivas e atributos dos reis-festeiros}

Os estudos sobre os papéis sociais que a alimentação desempenha na organização da vida social têm revelado fenômenos como exercícios de poder dos chefes e a distribuição da comida; os laços de parentesco ao longo dos quais se move o alimento, em suas funções de nutrição e de exibição; a competição por prestígio entre fazendeiros e assim por diante (Mintz, 2001, p. 32). Em todas as sociedades tradicionais as dádivas feitas sob forma de comida têm um papel de grande importância para estabelecer e reforçar laços de solidariedade. Por trás do sistema de trocas e dádivas, codificados por regras instituídas pela população do lugar, há sempre duas motivações: o desejo de dividir alimentos com a população, explicado pela vontade de manter a prática do festejo enquanto tradição local, e a oportunidade de obter prestígio, encoberta por uma generosidade, expressa por uma ostentação de riqueza, de poder, de capital simbólico (ver Bourdieu, 1989). Esse capital na maioria das vezes é constituído por uma doação de uma quantidade visível de alimentos ou cabeças de animais que serão abatidos e transformados em alimentação no dia do banquete.

A preparação do banquete na pequena cidade do sul-mineiro segue um ritual: começa com a matança de animais, a preparação das sobremesas, tarefa realizada por doceiras, um mês antes da data do banquete. "Preparar" e "cozinhar" a alimentação da festa tem um sentido especial no repertório masculino. Em Silvianópolis, como em Dolu (Melanésia) e em grande parte da Oceania, os homens cozinham nas grandes ocasiões e as mulheres ficam com a cozinha ordinária. As mulheres são responsáveis pela confecção dos doces, elaboram com antecedência em suas próprias cozinhas, sendo assim, as doceiras no dia do banquete não conseguem ofuscar a visibilidade masculina no banquete. Daí vem o prestígio associado aos "bons cozinheiros", decisão importante dos festeiros ao eleger cozinheiros com habilidades culinárias, para garantir o sucesso do banquete.

A escolha do cardápio também é tarefa dos festeiros, é um verdadeiro culto às origens, à vida colonial e à ruralidade contida na cultura mineira. Ao cozinheiro compete a arte de saber dosar os condimentos para uma quantidade maior de alimentos. Os condimentos representam a perfeição da arte culinária. A cozinha mineira mantém sua identidade 
por meio de alguns ingredientes, como a banha de porco, o rigor dos refogados, a leitoa assada, o tutu de feijão, frango de panela, sempre com sabor e aroma do cheiro verde que finaliza o prato intensificando seu colorido. Paulo Rogério, cozinheiro explica os segredos de uma boa farofa:

"Primeiro você refoga carne moída na banha de porco, junto com sal, cebola, alho. Vai colocando milho verde, ervilha, uva passa, azeitona picadinha e depois a farinha de milho."

A receptividade sensorial intervém na maioria das vezes mais que o tempo teórico do cozimento; o que informa sobre a evolução do cozimento e sobre a necessidade de aumentar ou abaixar o calor é o cheiro que vem do prato que está sendo preparado. Nos homens que se interessam pela arte culinária em Silvianópolis, constata-se uma múltipla memória: memória da aprendizagem, memória dos gestos vistos, das consistências, para saber o momento certo para tirar a farofa para não deixá-la queimar ou o tempo certo para dar ponto no tutu de feijão. Na confecção do grande banquete exige-se do cozinheiro-chefe uma inteligência programadora: perícia com o tempo de preparação e de cozimento, saber intercalar seqüências, a sucessão e a repetição de pratos a serem servidos para atender a um número grande de pessoas. As técnicas de preparação de alimentos são sujeitas aos mesmos fenômenos da memória oral: invenções, esquecimentos, improvisação, adaptação, simplificação, mal-entendidos (Valeri, 1989, p. 192).

As escolhas alimentares são determinadas por um código cultural que determina o paladar, código este muitas vezes inconsciente, às vezes racionalizado por uma ideologia e sua prática, e que expressa profunda consciência de identidade e de etnicidade. A posse da grande quantidade de alimentos, ou o controle de sua distribuição, da criação do cardápio, da escolha de cozinheiros e doceiras, são critérios fundamentais do poder político, atributos dos festeiros. Na Melanésia acredita-se que a produção, a abundância ou a fome dependem do mana, isto é do chefe, da sua força mágica, do seu controle sobrenatural da produção de recursos. No festejo sul-mineiro a força mágica, o controle da abundância de alimentos é de inteira responsabilidade dos organizadores da festa. Saber coletar donativos, saber administrar e organizar o grande banquete é uma tarefa que compete aos "bons festeiros". 
A transmissão de poder entre festeiros, realizada por meio da troca da coroa, requer ritos estabelecidos pelas tradições específicas. Esse rito denominado de reinado, momento em que os reis-festeiros sobem as montanhas da cidade para a cerimônia da troca de coroa junto da capela de Nossa Senhora do Rosário, situada no centro da cidade, é o momento crucial da festa. O festeiro é o símbolo mais visível, em torno do qual o povo constrói uma identidade coletiva e se reconhece enquanto comunidade solidária. O cortejo régio, teatralização do poder, mobiliza a população e cria no imaginário das pessoas o desejo da conquista do título de rei-festeiro, pois existe uma necessidade de exercitar o poder pelo menos uma vez na vida. Para assumir esta responsabilidade a sociedade exige da pessoa alguns dotes: competência, jeito para lidar com a população e principalmente comportamento moral, de acordo com uma ética estabelecida pela cultura da localidade. Priorizam-se muito mais valores morais do que financeiros na hora da escolha: para ser festeiro não precisa ser rico, basta estar dentro dos padrões estabelecidos pela moral cristã do que é ser um bom cidadão. Os valores morais e éticos de uma dada cultura expressam a visão de mundo do grupo social. Visão de mundo é o ethos, isto é o tom, o caráter, a qualidade devida, seu estilo moral e ético, sua disposição; é a atitude subjacente em relação a ele mesmo e ao mundo que a vida reflete (Geertz, 1989 , p. 143). Em todos povos as formas e os objetos de culto são rodeados por uma aura de profunda seriedade moral.

Sobre os padrões exigidos para exercer a prática de festeiro, ficam expressos na narrativa de Isabel, que já vivenciou a experiência por três vezes:

"A pessoa tem que tê responsabilidade, por exemplo se eles souberem que a pessoa bebe, eles não dão a festa, se souber que é amigado já não dão a festa. Tem que ser uma pessoa de peso, né? Porque a responsabilidade é muito grande. Faz e chega lá, e o que quer pegar chega lá, se eles estão de acordo eles dão, se acham que não estão eles não dão. Agora mesmo, no dia 13, no dia do levantamento do mastro, tava eu e o companheiro meu, meu filho, e a outra irmã dele. Nós já tinha combinado de pegar junto, aí apareceu mais uma lá, e aí falaram vai fazer votação" 
Nos depoimentos coletados percebem-se ainda rivalidades, embates, concorrência no momento da escolha dos festeiros do ano seguinte, e ainda o grande desejo de assumir o papel de rei e rainha. Fátima, festeira em 2003, relata:

"Sempre tive vontade de fazer uma festa desta, surgiu oportunidade, então estou realizando uma coisa que queria a muito tempo, fazer uma festa do Rosário. Estou satisfeita. Você fica emocionada, porque a cerimônia na casa da santa é muito bonita. Têm as coroas, ontem nós subimos com as coroas em reinado, os congadeiros na frente e o povo atrás. Ontem nós subimos com as coroas. Eu fiquei o ano inteiro com uma coroa e o outro festeiro com outra. Ontem nós subimos, lá na casa da santa, eu deixei a coroa. E hoje a gente sobe de novo em reinado e entrega a coroa para os novos festeiros do ano que vem, que já foram determinados no dia 15 [de junho]."

A abundância de alimentos torna possível a "generosidade", e por vezes até o esbanjamento suscita respeito e admiração dos hóspedes, congadeiros e visitantes. A fartura tem uma função simbólica e social que vai além da função nutritiva do alimento. A fartura da alimentação tem um papel renovador, fortalece o corpo enquanto o reinado dos reis-festeiros acompanhados de congadeiros por meio da devoção no rito da troca de coroa, tem uma dimensão de renovação e purificação da alma. Para quem o organiza, o banquete é uma maneira de manifestar riqueza. A fartura é grande e as sobras são desconsideradas. E uma forma de evitar contaminação é se desfazer das sobras. O excedente é jogado no lixo, para evitar o perigo contaminador.

Sobre a destruição dos excessos de alimentos no banquete do Rosário, Francisco acrescenta informações, diz:

“Toda comida que sobra não é reaproveitada, é destruída, não é doada a ninguém, para evitar que alguém venha comer uma comida deteriorada. Ontem [sábado, 28-06-03] foi jogado 100 quilos de comida fora. Só de leitoa uns 40 quilos."

$\mathrm{Na}$ narrativa do cozinheiro Roberto fica presente a fartura de carne e de bebidas ingeridas nos banquetes do final de semana do festejo: 
"Matamos 70 leitoas, comprou 600 quilos de carne de boi, 300 quilos de leitoa, 400 quilos de frango. Matamos 3 ou 4 dias antes da festa. Pra começá, os congadeiros tem que vir, e tem que ter comida boa. Serve pinga, refrigerante a vontade. Ontem servimos 150 litros de refrigerante e 100 litros de pinga".

A cachaça ao lado da comida desde o tempo da colônia fazia parte integrante dos rituais mineiros, tanto profanos como religiosos, das comemorações, dos ritos fúnebres e celebrações familiares. Não existe rito sem o consumo da cachaça. Existe uma lei democrática para o uso da cachaça em dias de festa: possibilita convívio entre moradores e visitantes, entre ricos e pobres. A embriaguez parece tolerável e permitida nestas ocasiões, sendo assim, a bebida propicia alegria e companheirismo. Eschwege, falando da alimentação de escravos nas minas de ouro, relata que os conterrâneos se assentavam juntos e comiam da mesma gamela e, quando conseguiam alguma bebida a dividiam entre os companheiros (apud Scarano, 2001, p. 479).

Todo ato solene que reúne indivíduos concretiza-se pela realização de uma refeição em comum. A partilha da comida e da bebida estabelece uma fraternidade que remete a uma das expressões de solidariedade básica da comunidade. A ostentação verifica-se por meio de trocas, todavia a ostentação sem trocas provoca inveja e expõe aos ataques da feitiçaria (Valeri, 1989, p. 198).

Faz parte ainda do estatuto do festejo a disciplina de aproximação à mesa. Os ternos de congos seguem uma ordem e a partir do meio-dia, em forma de desfile entram no barracão, espaço construído para servir refeição aos grupos de congadas. O barracão representa as imagens da cozinha mineira, constituído de copa e cozinha, lugares das relações de intimidade. A copa é representada por diversas salas, espaços reservados para as mulheres e homens da congada; cada grupo ocupa uma sala com os comportamentos e modos exigidos do comer à mesa. Mantém-se ainda o tabu dos ternos de congo comerem junto com o povo, sistema que exprime a importância dos papéis sociais. $\mathrm{O}$ sistema ideológico do festejo tende a privilegiar a identidade dos grupos de congos em detrimento da população em geral. $\mathrm{O}$ banquete, expressão da comunidade, representa as hierarquias e as relações de poder. Essas relações de poder expressam-se pelo lugar que cada um ocupa na mesa, pelos critérios de repartição dos alimentos. 
Existe uma preocupação grande com relação à higiene dos alimentos, à escolha dos pratos e à forma de confeccioná-los. As características fundamentais da alimentação saudável são a variedade, a preferência por alimentos cozidos, feitos na hora de servir e de fácil digestão. Assim, por exemplo, maionese caseira é totalmente abolida pelo perigo de contaminação. Para Tanício, morador da localidade: "a salada mais fácil é de alface e tomate, aquela que se faz na mesa", servida fresquinha sem perigo algum de contaminação.

A cozinha por sua vez, é palco de "homens cozinheiros" e de "mulheres ajudantes" (descascando batatas, lavando louça) e de demonstração de utensílios da cozinha regional, ou seja, grandes tachos, panelas e grandes colheres-de-pau, necessárias para a movimentação do grande volume de iguarias. A cozinha desempenha uma função cultural. Os pratos são apresentados uns após outros e idênticos a todos os convidados, o menu consiste em: salada, carne (de boi, frango ou porco), farofa, tutu de feijão, arroz e farta sobremesa. Tanício comenta algumas estratégias adquiridas em sua prática como cozinheiro:

"Alguns pratos já fica pronto direto, se for fazer tudo no dia não dá conta, ah! O que faz a diferença é que de madrugada já põe o feijão para cozinhar, feijão faz um saco de uma vez só, faz feijão com torresmo, quando não tem, põe bacon no meio. Tem carne que é cozida e frita, tem que fazer e ensacar e pôr no freezer, quando chega o dia da festa, por exemplo a festa é amanhã ou depois de amanhã, aí ela volta no fogo pra fritar, aí põe molho, bastante cebola de cabeça e serve ela quente. $\mathrm{Na}$ festa não serve comida fria."

As sobremesas (doces de leite, batata, abóbora, mamão, laranja) são servidas do lado de fora do barracão em grandes potes, com a mesma fartura com que eram servidas as sobremesas no tempo da escravidão. Os doces são preparados com certa antecedência, guardados em balde e grandes latas e servidos no final de semana do banquete. Esses preparativos começam um mês antes. Segundo D. Terezinha, doceira tradicional, os doces recebem bastante ponto, sendo assim, não precisam ser conservados em geladeira. Para D. Terezinha, o momento mais emocionante da festa é o momento da partilha das sobremesas. Sentese reconhecida pela gratidão dos participantes: 
"Ah! Para mim eu gosto dos doces, repartir os doces pro povo, eu gosto de ver o povo comer a comida, comer os doces, o povo cantando, agradecendo a gente, eu acho tudo muito... o povo dançando o congo [risos], na despedida quando esse povo vai embora, esse povo agradece e vai embora. Eles agradecem, eles falam assim: aquelas doceiras, agradecendo, muito obrigado as doceiras, muita saúde, o ano que vem se Deus quiser a gente volta, aí a gente até chora, né?”

Embora os cardápios do banquete sejam os mesmos para os diferentes públicos (congadeiros e população em geral), algumas leis da honra aristocrática ainda são respeitadas: congadeiros comem em pratos de louça enquanto a população utiliza pratos descartáveis. Moradores e visitantes esperam a refeição ser servida do lado de fora do barracão; alguns impacientes reclamam pela demora, todavia a maioria aproveita o momento para rever amigos e "jogar conversa fora". Bakhtin, em seu texto $O$ banquete em Rabelais, alega que: "durante a festa, a voz do tempo fala principalmente do futuro. $\mathrm{O}$ triunfo do banquete toma a forma de antecipação de um futuro melhor" (2002, p. 250). Nos votos de um futuro melhor estão contidos: realizações pessoais, retorno à festa, reencontro de amigos e ainda projetos que garantam a manutenção da tradição e o sucesso da próxima festa.

\section{A devoção e a face ritualística da crença}

A devoção contida na festa do Rosário em Silvianópolis está ligada às tradições religiosas ${ }^{2}$, às generosidades, ao reencontro de amigos e ao comer coletivo. A religiosidade dessa população frutificou do apego à face ritualística da crença, daí a sua índole lúdica (Arruda, 1990, p. 177).

2 Utilizo-me do conceito de tradição inspirada em Raymond Williams (1979, p. 118): "A tradição é na prática a expressão mais evidente das pressões e limites dominantes e hegemônicos. É sempre mais do que um segmento inerte historicizado; na verdade, é o meio mais prático de incorporação mais poderoso. O que temos que ver não é apenas uma tradição, mas uma tradição seletiva: uma versão intencionalmente seletiva de um passado modelador e de um presente pré-moldelado, que se torna poderosamente operativo no processo de definição e identificação social e cultural." 
A festa do Rosário reflete a visão de mundo que a população local tem, é "o quadro que elabora das coisas como elas são na simples realidade, seu conceito de cultura, se si mesmo, da sociedade" (Geertz, 1989, p. 144). A crença religiosa, a devoção à santa e o ritual confrontam e confirmam-se mutuamente. A relação significativa entre a tradição que o povo conserva e a ordem geral da existência dentro da qual ela se encontra é o elemento essencial da festa. O lado sagrado da festa é aquele que contém o sentido da obrigação intrínseca; encorajando a devoção, induz sua prática e reforça o compromisso emocional. A articulação do sagrado com o lado mundano do festejo estabelece regras para a orientação da conduta e dos papéis dos participantes.

O festejo funciona ainda como mecanismo de neutralização dos conflitos e diferenças, cria uma convivência ilusória de que a sociedade é igualitária e solidária. O rito é ao mesmo tempo espaço de encontros, como também espaço da memória, espaço de sociabilidades e de hierarquias. A festa, uma vez desvinculada das programações da Igreja Matriz, demonstra seu caráter profano; a religiosidade e a devoção têm uma feição visual e lúdica, demonstrando a dimensão leiga e profana da religiosidade mineira.

Nossa Senhora do Rosário teve sua igreja destruída no início do século XX; possui hoje uma capela, com as portas abertas aos devotos uma vez ao ano: no mês de junho, ocasião da Festa dos Congos. Nossa Senhora do Rosário dos escravos negros ${ }^{3}$, tão reverenciada no século XVIII mineiro, foi carnavalizada e desacatada por colonos na religiosidade cotidiana. Mesmo em Portugal costumava-se inserir a Virgem em contextos profanos, carnavalizando sua função (Mello e Souza, 1986, p. 116).

A alimentação do banquete difere do cotidiano do trabalhador e o cardápio difere do dia-a-dia. O trabalhador procura ganhar a vida e o alimento no combate é sinônimo de trabalho. No comer coletivo da festa o alimento significa troca, generosidade, tradição. A tradição é seletiva de um passado modelador. Certas práticas são escolhidas enfaticamente, são modelos do passado mantidos no presente, outras são colocadas de lado ou negligenciadas. A tradição é um aspecto da organização social e cultural contemporânea (Williams, 1979, p. 120).

3 Sobre Nossa Senhora do Rosário como santa popular dos negros escravos, ver Laura de Mello e Souza em O Diabo e a Terra de Santa Cruz (1986). 
A imagem da festa de Nossa Senhora do Rosário formou-se efetivamente durante séculos. Para Bernadete, moradora local, a festa: "significa 223 anos que o povo vem no festejo, ajuda o festejo, come no festejo, é uma troca. Aqui tem gente daqui, de fora, tem rico, tem pobre, é uma união."

Este sistema de trocas, com o passar dos anos foi crescendo e adquirindo sentido novo, filtrando e selecionando anseios da população, aceitando idéias novas que surgem na experiência popular da própria festa. A festa cada ano adquire nova visibilidade, nova roupagem. As ruas da cidade exibem um colorido especial, expresso em alegorias corporais e musicais dos ternos de congada. A festa do Rosário é a combinação entre o ritual coletivo e a diversão coletiva. A festa promove uma imensa ilusão comunitária em oposição à vida ordinária, desgastante e antagônica. $\mathrm{O}$ festejo promove uma união, renova as energias e lida com as barreiras sociais de forma não usual. A festa se opõe ao ritmo regular e rotineiro da vida. "Vale dizer que a festa é necessariamente desordem, no sentido de transgressão das interdições e das barreiras sociais usuais. Ela promove uma imensa fusão comunial, por oposição à vida ordinária, que classifica e separa, que desgasta as energias da sociedade" (Perez, 2002, p. 31).

Em Silvianópolis a multidão em júbilo enche as ruas. Esta multidão não é uma multidão qualquer, existe uma organização sensível, é um todo organizado à maneira popular. Os participantes reunidos demonstram o aspecto efervescente da festa. ${ }^{4}$ A festa do Rosário é ao mesmo tempo ritual e festividade. É cerimônia, solenidade, acontecimento social e divertimento. "O divertimento corresponde à função expressiva, recreativa e estética da festa.” (Perez, 2002, p. 20) A celebração instaura uma forma lúdica de vivenciar a vida social. A festa tem sempre seu aspecto ritual, ela é ao mesmo tempo entretenimento, cerimônia e solenidade.

A oralidade constitui o elemento essencial da comunidade na manutenção do festejo. A conversação sobre a celebração do Rosário está

4 Sobre a efervescência da festa, ver Léa Freitas Perez, no texto Antropologia das efervescências coletivas. Apóia-se em Durkheim para as explicações sobre o estado de efervescência das massas como um dos caracteres da festa, que tem como efeito a aproximação dos indivíduos. 
em todo lugar, na rua, nas casas, na família dos festeiros. O intercâmbio de informações exige uma correlação de gestos e de corpos, presença de vozes e de enfoques marcados pela paixão, pela inspiração que revela a lógica pessoal dos moradores. Informações complementares são necessárias para interpretar as mensagens orais: desde os gestos realizados com as mãos, a entonação da voz, movimento do rosto. $\mathrm{O}$ povo sente a sua unidade, a comunidade vivencia de forma aglomerada uma estética corporal. Ao considerar a cultura como ela é pratica$\mathrm{da},{ }^{5}$ leva-se em conta não a mais valorizada pela representação oficial, mas pelas tradições orais, criatividades práticas e atos da vida cotidiana.

\section{Referências bibliográficas}

ABDALA, Mônica Chaves. Receita de mineiridade: a cozinha e a construção da imagem do mineiro. Uberlândia: EDUFU, 1997.

ARRUDA, M. do Nascimento. Mitologia da mineiridade. São Paulo: Brasiliense, 1990.

BARÃO DE ESCHWEGE, Guilherme. Diário de uma viagem do Rio de Janeiro à Vila Rica, na capitania de Minas Gerais, no ano de 1811. São Paulo: Imprensa oficial do Estado, 1936.

BAKHTIN, Mikhail. A Cultura popular na idade Média e no Renascimento. São Paulo: Hucitec/AnnaBlume, 2002.

BOURDIEU, Pierre. Poder simbólico. Lisboa: Difel/Bertrand Brasil, 1989.

GIARD, Luce. Cozinhar. In: CERTEAU, Michel et. al.. A invenção do cotidiano. Petrópolis: Vozes, 1996.

GEERTZ, CLIFFORT. A interpretação das culturas. Rio de Janeiro: LTC, 1989.

JOANNĖS, Francis. A função social do banquete nas primeiras civilizações. In: FLANDRIN, Jean-Louis; MONTANARI, Massimo (org). História da alimentação. São Paulo: Estação Liberdade, 1998.

MELLO E SOUZA, Laura de. O diabo e a Terra de Santa Cruz. São Paulo: Cia das Letras, 2000.

5 "Os hábitos alimentares de uma determinada sociedade num dado tempo estão ligadas por coerências internas, invisíveis, mas reais" (Luce, 1994, p. 245). 
MINTZ, Sidney. Comida e antropologia: uma breve revisão. In: Revista Brasileira de Ciências Sociais. ANPOCS, v. 16, n. 47, p. 31-43, out/2001.

PEREZ, Léa Freitas. Antropologia das efervescências coletivas. In: PASSOS, Mauro (org.). A festa na vida: significado e imagens. Petrópolis: Vozes, 2002.

PORTELLI, Alessandro. Forma e significado na História oral. A pesquisa como um experimento em igualdade. In: Projeto História, 14. Cultura e Representação. PUC-SP, p. 7-25, 1997.

SCARANO, Julita. Bebida Alcoólica e sociedade colonial. In: JANCSÓ, István; KANTOR, Íris. (org.) Festa, cultura e sociedade na América portuguesa. Vol. 2. São Paulo: EDUSP/Imprensa Oficial, 2002.

VALERI, René. Alimentação In: Enciclopédia Einaudi. Vol. 16. Imprensa Nacional-Casa da Moeda, 1989.

WILLIAMS, Raymond. Marxismo e Literatura. Rio de Janeiro: Zahar, 1979.

\section{Fontes orais}

Isabel: festeira eleita para a festa de 2004. Entrevistada em 27 de agosto de 2003.

Roberto: cozinheiro profissional. Cozinha em diferentes festejos no sul de Minas. Entrevistado em 29 de junho de 2003.

Fátima: festeira em 2003. Entrevistada em 29 de junho de 2003.

Francisco: ajudante na administração da cozinha durante a festa de 2003.

Entrevistado em 29 de junho de 2003.

Bernadete: moradora local. Entrevistada em 29 de junho de 2003.

Paulo Rogério: cozinheiro na festa de 2003. Entrevistado em 29 de junho de 2003.

Terezinha: doceira, moradora local. Entrevistada em 11 de março de 2003. Tanício: cozinheiro, morador da localidade. Entrevistado em 11 de março de 2003.

Resumo: Imagens e significados do festejo são enfocados a partir do comer coletivo no banquete servido aos congadeiros e ao público em geral na celebração em homenagem a Nossa Senhora do Rosário, em Silvianópolis, cidade do sul de Minas. Tratase de uma consagração extra-lógica, com uma temporalidade 
não linear, com códigos diferentes dos usuais. A festa é marcada pelo lúdico, com emoções oriundas de devoções, de ritos e de tradição. O reino do sagrado no festejo produz o efeito contagiante de aproximação entre pessoas e a manutenção da celebração. A articulação do sagrado com o lado mundano do festejo estabelecem regras para a orientação da conduta e dos papéis dos participantes. O rito baseado em sistema de trocas e dádivas reforça laços de sociabilidades, as hierarquias sociais e exercícios de poder.

Palavras-chave: alimentação em festejo; trocas e dádivas; papéis sociais.

Images and Meanings of the Rosary Feast

ABSTRACT"The core from the feast's images and meanings comes from collective feeding costumes contained in the feast served to congadeiros and the general public, celebrating in a special homage the Rosary Lady on the Silvianopolis, a small town located in the southern side of the Minas Gerais. It is an extra-logical consecration with a non-linear temporality, with different codes from the ordinary ones. The feast is remarkable due to its ludic features, with emotions arisen from devotions, rites and tradition. The sacred domain of the feast produces the catching effect to approach people from each other and to maintain the celebration. The articulation of the sacred feature with the worldly side of the feast sets the rules towards the orientation that guides the conduct and role of the participants. The rite is based on exchanging system and gifts, reassuring sociable bonds, social hierarchies and power exercises.

KEYWORDS: Feeding in feast; exchanges and gifts; social roles. 